\title{
ESTUDOS SOBRE UM ABRIGO PARA PESSOAS EM SITUAÇÃO DE RUA NA CIDADE DE PRESIDENTE PRUDENTE - SP
}

\author{
Ana Flávia Montagnoli Postinguel, Korina Aparecida Teixeira Ferreira da Costa \\ Universidade do Oeste Paulista - UNOESTE, Curso de Arquitetura e Urbanismo, Presidente Prudente, SP. Email: \\ korina.arq@gmail.com
}

\section{RESUMO}

O presente artigo aborda a população em situação de rua, evidenciando o surgimento desse fenômeno e o perfil desses indivíduos. O objetivo deste estudo foi elaborar um projeto de abrigo para a população de rua em Presidente Prudente, que atenda às suas necessidades e possibilite a inclusão social. A metodologia consta de pesquisa bibliográfica e levantamentos in locu. Concluímos que as pessoas que vivem nas vias públicas formam um grupo heterogêneo, mas que possui em comum a situação de vulnerabilidade social. Vemos que a maioria delas são dependentes químicos e, por essa razão, é necessário que os abrigos forneçam apoio e tratamento psicológico para que que sejam reinseridas na sociedade.

Palavras-chave: População em situação de rua, Inclusão Social, Abrigo, Diretrizes Projetuais, Presidente Prudente - SP.

\section{ARCHITECTURAL DESIGN OF A SHELTER FOR STREET POPULATION IN THE CITY OF PRESIDENTE PRUDENTE - SP}

\begin{abstract}
This article addresses the street population, showing the emergence of this phenomenon and the profile of these individuals. The objective of this study was to elaborate a project of shelter for the population in Presidente Prudente, which meets their needs and enable social inclusion. The methodology consists of bibliographic research and surveys in locu. We found that people living in public roads form a heterogeneous group, but which has in common the situation of social vulnerability. We see that most of them are drug addicts and, for this reason, it is necessary that the shelters provide support and psychological treatment to which they are reinserted into society.
\end{abstract}

Keywords: Street population, Social Inclusion, Shelter, Design guidelines, Presidente Prudente - SP. 


\section{INTRODUÇÃO}

O presente artigo resulta de pesquisas e levantamentos desenvolvidos no TCC do curso de Arquitetura e urbanismo da Unoeste. Através desse estudo, constatou-se que atualmente há um grande número de pessoas que moram nas ruas e esses formam um grupo heterogêneo. Essa circunstância provoca danos à cidade como um todo e não só aos envolvidos como a maioria pensa, pois de acordo com Ogg (2014), os moradores de rua ficam doentes por causa das péssimas condições de higiene em que vivem; a população sente medo por que pensa que esses indivíduos podem lhe causar algum mal; a falta de qualificação profissional os impedem de conseguir um emprego formal e, por último, percebe-se que a apropriação e o uso inadequado do espaço público acabam destruindo a cidade.

Segundo dados do Centro Pop (2018), há 270 pessoas em situação de rua em Presidente Prudente, onde será implantado o Abrigo. Para oferecer apoio a esses indivíduos, a cidade conta com duas instituições, sendo o Centro Pop e o Serviço de Acolhimento, entretanto há somente 50 vagas no Abrigo.

Diante do exposto, vê-se que se faz necessário a pesquisa, cujo objetivo é esclarecer o perfil dos moradores de rua, bem como suas necessidades, para então desenvolver o projeto arquitetônico de um Abrigo temporário que ofereça apoio a essas pessoas pelo tempo que for necessário e possibilite a inclusão social.

\section{METODOLOGIA}

A metodologia de pesquisa utilizada é a qualitativa, apoiando-se também em coleta de dados quantitativos. Inicialmente o estudo foi feito a partir de pesquisa bibliográfica, utilizando-se artigos, dissertações e notícias de jornais que abordam a população em situação de rua. Houve ainda a visita às duas principais instituições em Presidente Prudente que atendem a população de rua da cidade para entender o funcionamento do abrigo e pontuar seus pontos positivos e negativos.

Após todo o embasamento teórico do tema proposto, foram feitos levantamentos in locu do terreno escolhido para a implantação e seu entorno. Através do conhecimento do entorno do terreno e de suas condicionantes foi possível desenvolver as diretrizes projetuais.

\section{BREVE HISTÓRICO DO SURGIMENTO DA POPULAÇÃO EM SITUAÇÃO DE RUA}

Percebe-se que não há unanimidade sobre o surgimento da população em situação de rua. A maioria dos autores consideram que esse fato se manifestou como um dos resultados da Revolução Industrial, entretanto existem alguns relatos na história antiga de indivíduos que moravam nas ruas, como por exemplo o filósofo grego Diógenes que se dizia autossuficiente. (BRASIL. Secretaria de Direitos Humanos da Presidência da República, 2013)

No Brasil, os primeiros registros de pessoas em situação de rua são da época colonial, quando os escravos libertos não tinham onde morar e trabalhar. Com a vinda dos imigrantes no fim do século XIX, essa situação piorou, porque além de haverem muitos moradores de rua, começaram a surgir os cortiços na periferia das cidades. (ANDRADE; COSTA; MARQUETTI, 2014)

A partir daí a desigualdade social só aumentou, pois o desenvolvimento do capitalismo e as modificações dos direitos trabalhistas fizeram com que várias pessoas ficassem sem emprego e moradia. (IANNI, 1994 apud CERQUEIRA, 2011) 
Ocorre então, desde a década de 1970, uma intensa migração de pessoas para as grandes cidades em busca de um bom trabalho e boas condições de vida, o que acaba tornando escassas as vagas de emprego. Além disso, a globalização obriga as empresas a produzirem mais em menor tempo, fazendo o uso de máquinas e consequentemente ocorre a redução de mão-de-obra. Verifica-se assim um aumento exagerado do desemprego e como várias pessoas não conseguem se manter, elas fazem uso do trabalho informal ou são obrigadas a viver nas ruas. (OGG, 2014)

Atualmente, aliado a essa condição de pobreza extrema, há outros fatores que fazem pessoas irem morar nas ruas, como: problemas familiares, vício em drogas ou álcool, doenças mentais, entre outros. Apesar da assistência social oferecer ajuda a esses indivíduos, vários deles não a aceitam porque preferem a liberdade que a rua lhes proporciona.

\section{PERFIL DOS MORADORES DE RUA EM PRESIDENTE PRUDENTE}

Com o passar dos anos, a quantidade de pessoas que moram nas ruas vem só aumentando e essa situação decorre, principalmente, da má concentração de renda e ineficiência das políticas públicas voltadas a essa população. (SILVA; PARRÃO, 2012)

Em Presidente Prudente, sabe-se que o número de moradores de rua cresceu muito do ano de 2012 até atualmente. Conforme os dados do Portal Prudentino (2012), havia nesse mesmo ano, 86 pessoas vivendo nas ruas. Nos dias de hoje, segundo dados do Centro POP de Presidente Prudente (2018), há 270 indivíduos em situação de rua.

Em relação ao número atual de pessoas em situação de rua, o Centro POP (2018) afirma que $77 \%$ são homens e $20 \%$ são mulheres. Os $3 \%$ restantes incluem bissexual, trans ou não declarado. Sobre a faixa etária, sabe-se que a maioria possui entre 31 e 40 anos, correspondendo a $31 \%$ do total.

Outra informação fornecida pelo Centro POP (2018) diz respeito às substâncias psicoativas usadas por esses indivíduos. Pelo gráfico percebe-se que de todos os moradores de rua contabilizados, somente 13 negam o uso. A maioria deles, equivalente a $39 \%$, utiliza múltiplas drogas e $30 \%$ são dependentes do álcool. Os $31 \%$ restantes são aqueles que utilizam maconha, crack ou possuem algum transtorno mental associado ao uso de drogas.

Gráfico 1. Substâncias psicoativas usadas pelos moradores de rua

\section{Principais substâncias psicoativas}

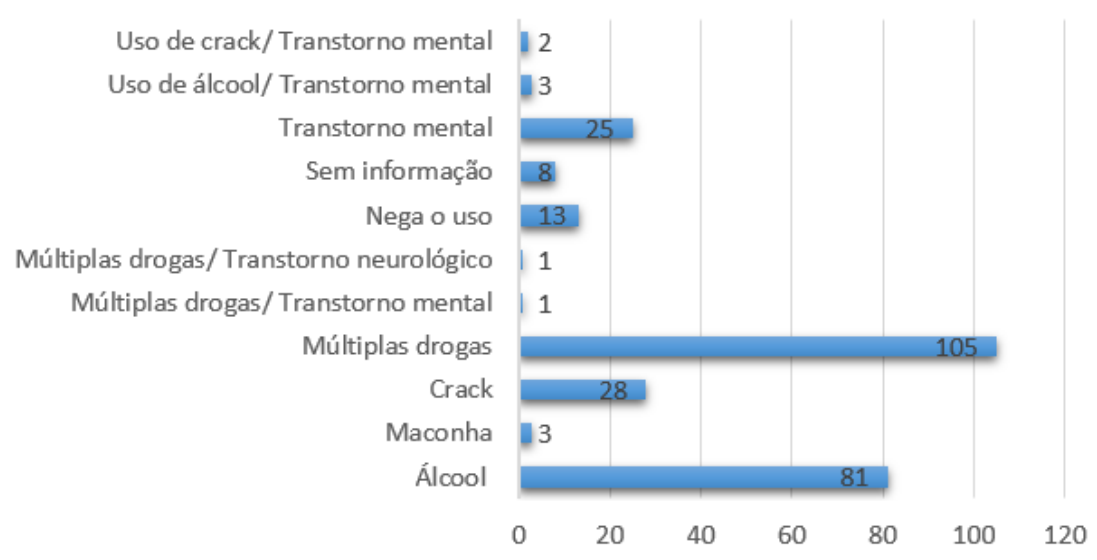

Fonte: Autoras (2018), com base nos dados do Centro POP (2018) 
Em relação a quantidade de usuários por serviço, percebe-se através do gráfico abaixo que quase $50 \%$ utilizam o Centro POP, cerca de $25 \%$ são atendidos pelo SEAS (Serviço Especializado em Abordagem Social) e $10 \%$ são abrigados pelo SAPRU (Serviço de Acolhimento para situações de rua em Presidente Prudente).

Gráfico 2. Usuário por serviço

USUÁRIO POR SERVIÇO

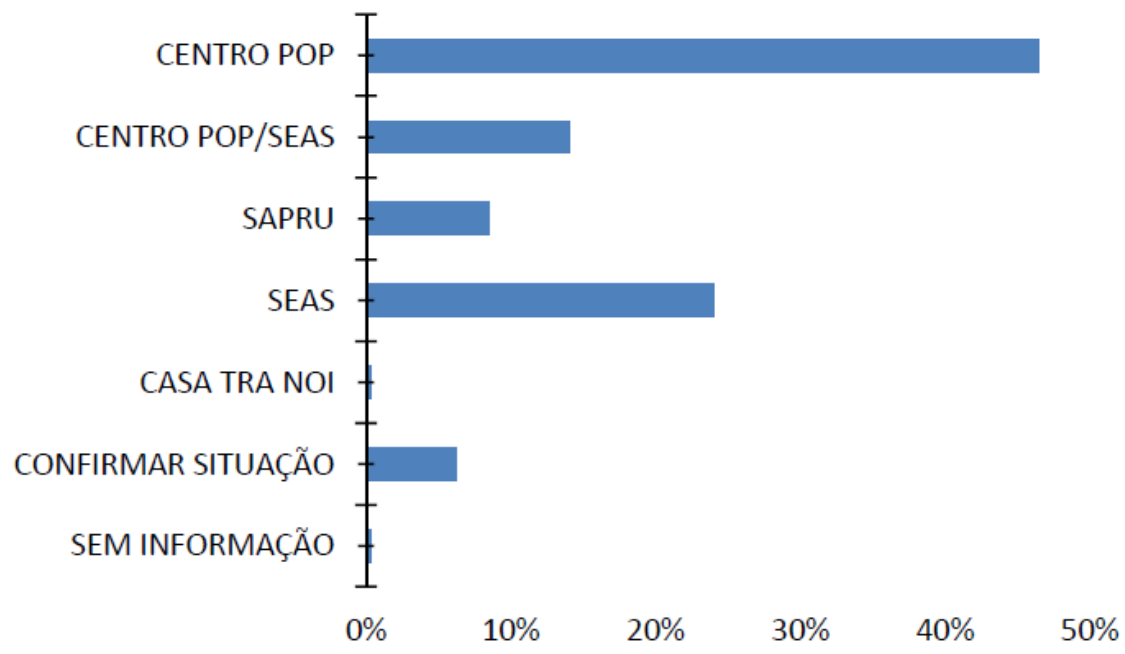

Fonte: Centro POP (2018)

\section{DIRETRIZES PROJETUAIS E CONCEITO ARQUITETÔNICO}

A proposta refere-se a um projeto de Abrigo temporário para a população de rua em Presidente Prudente. A edificação visa acomodar homens e mulheres pelo tempo que for necessário, de modo que eles se sintam livres para somente fazerem as refeições ou morarem provisoriamente.

O terreno escolhido para a implantação está localizado na Zona Leste de Presidente Prudente, mais especificamente, na Avenida Brasil, ao lado do Poupatempo. Essa escolha se deve ao fato dele estar próximo às áreas de maior concentração de moradores de rua, que são o edifício abandonado da CATI e a Praça da Bandeira. Além disso, apresenta vantagens como: grandes dimensões e o bairro onde está inserido possui boa infraestrutura. $\mathrm{O}$ acesso principal ao lote se dá pela Avenida Brasil e o secundário pela Rua Mendes de Moraes. 
Figura 1. Localização do terreno escolhido

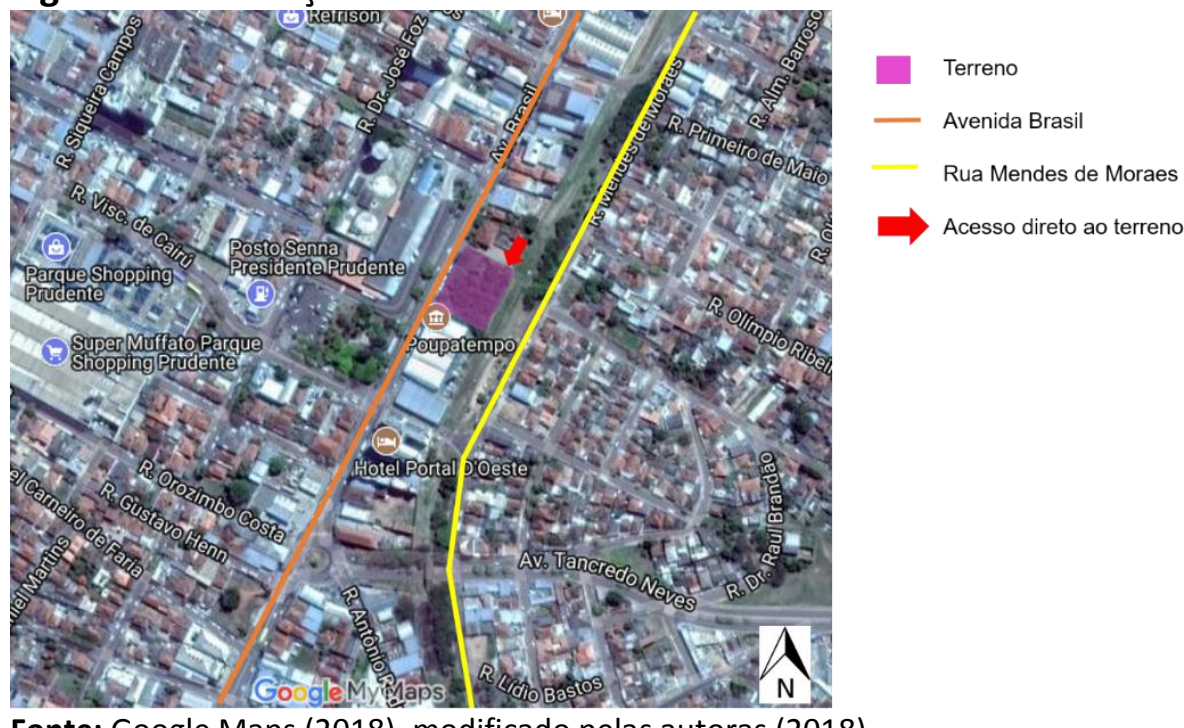

Fonte: Google Maps (2018), modificado pelas autoras (2018)

O principal objetivo do edifício é proporcionar a inclusão social, oferecendo meios para a integração das pessoas em situação de rua à comunidade de maneira digna. Dessa forma, além do acolhimento, ele contará com: tratamento para dependentes químicos, para restabelecer a saúde desses indivíduos; atendimento psicológico, com o intuito de minimizar os traumas advindos da situação em que se encontravam; aprendizagem e oficinas para obterem qualificação e voltarem ao mercado de trabalho; cultivo da horta comunitária, a fim de terem uma ocupação e realização de mini feiras para venderem os produtos feitos nas oficinas, pois assim ganharão um pouco de dinheiro.

Visto que a população de rua perdeu os vínculos sociais e, por isso, se encontra em situação de exclusão, o conceito do projeto é estimular o convívio entre eles e as demais pessoas. Por essa razão, o programa de necessidades será dividido em dois blocos e no meio deles haverá uma praça aberta. Essa servirá como caminho para aqueles que moram no bairro atravessarem o quarteirão e será o local onde acontecerão minifeiras para os moradores venderem os produtos feitos nas oficinas. Além disso, as oficinas oferecidas no abrigo poderão ser frequentadas por todos em um período específico.

A topografia do terreno também foi considerada, pois o grande desnível de $3,70 \mathrm{~m}$, possibilitará que os dois blocos apresentem um subsolo na parte mais baixa do lote. 0 edifício principal possuirá quatro pavimentos: no subsolo constam as oficinas e biblioteca; no térreo estão a administração, setor de saúde e salas de aula; no 10 pavimento e 20 pavimento ficam os dormitórios, para proporcionar mais privacidade aos moradores. 0 outro bloco terá o setor de serviço e refeitório.

$\mathrm{Na}$ figura abaixo consta a implantação, na qual fica evidente a disposição dos dois blocos e a localização da entrada principal na fachada lateral para que as pessoas tenham maior contato com a praça. Houve a integração da horta com a praça, localizadas entre os edifícios, para que ambas sejam utilizadas por toda a população do bairro. 
Figura 2. Croqui da implantação

Fonte: Autoras (2018)

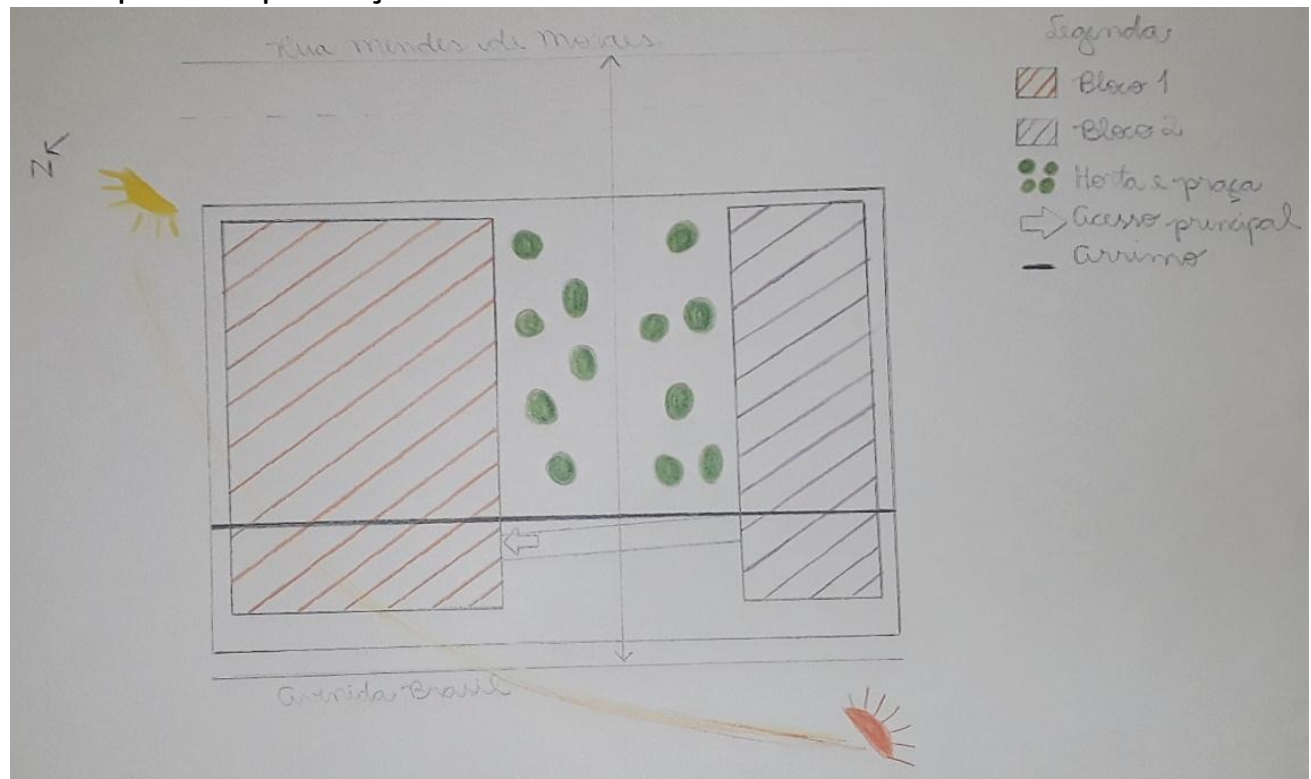

Além dessas diretrizes, é levado em conta a acessibilidade, baseada nas orientações da NBR 9050, e o conforto térmico do edifício, posicionando os ambientes de maior permanência voltados para a face leste, utilização de brises na fachada de maior insolação e aproveitamento da ventilação natural.

\section{CONCLUSÃO}

A partir dessa pesquisa, pode-se concluir que apesar dos moradores de rua formarem um grupo heterogêneo, todos eles estão em uma situação de vulnerabilidade social, sofrendo preconceito e violência. Esse problema afeta também a cidade, pois ao se apropriarem indevidamente do espaço público, acabam degradando-o e gerando insegurança no restante da população.

Em Presidente Prudente, verifica-se que as vagas ofertadas pelo Serviço de Acolhimento são insuficientes para a demanda da cidade e a instituição só abriga os dependentes químicos que estejam em tratamento. Dessa forma, é necessário a implantação de um abrigo que ofereça tratamento a esses indivíduos, pois além de diminuir o índice de sem teto, irá possibilitar a reinserção social.

\section{REFERÊNCIAS}

ANDRADE, L.; COSTA, S.; MARQUETTI, F. A rua tem um ímã, acho que é a liberdade: potência, sofrimento e estratégias de vida entre moradores de rua na cidade de Santos, no litoral do Estado de São Paulo. Saúde Soc., São Paulo, v.23, n.4, p.1248-1261, 2014. Disponível em: <http://www.scielo.br/pdf/sausoc/v23n4/0104-1290-sausoc-23-4-1248.pdf>. Acesso em: 09 mar. 2018.

BRASIL. Secretaria de Direitos Humanos da Presidência da República. Diálogos sobre a população em situação de rua no Brasil e na Europa: experiências do Distrito Federal, Paris e Londres, 2013.2 Disponível em:< http://www.sdh.gov.br/assuntos/bibliotecavirtual/promocao-e-defesa/publicacoes- 
2013/pdfs/dialogos-sobre-a-populacao-em-situacao-de-rua-no-brasil-e-na-europa-1>. Acesso em: 06 mar. 2018.

CERQUEIRA, Aramantha Sá Teles. Evolução do Processo Social População em Situação de Rua: um estudo sobre pobreza, necessidades humanas e mínimos sociais. 2011, $96 \mathrm{f}$. Trabalho de Conclusão de Curso (Bacharel em Serviço Social) - Universidade de Brasília, Brasília. Disponível em:< http://bdm.unb.br/bitstream/10483/2573/1/2011_AmaranthaSaTelesdeCerqueira.pdf >. Acesso em: 05 mar. 2018.

OGG, Helena D'Ávila. Centro de Assistência à População em Situação de Rua. 2014. 73 f. Monografia (Bacharelado em Arquitetura e Urbanismo) - Trabalho de Conclusão de Curso de Arquitetura e Urbanismo, Universidade Tecnológica Federal do Paraná. Curitiba. Disponível em:<

http://repositorio.roca.utfpr.edu.br/jspui/bitstream/1/2985/1/CT_COARQ_2014_1_01.pdf>. Acesso em: 29 out. 2017.

PORTAL PRUDENTINO. Prudente contabiliza 86 moradores de rua, diz SAS. Presidente Prudente, 07 fev. 2012. Disponível em: < http://portalprudentino.com.br/noticia/noticias.php?id=26893\&titulo=prudente-contabiliza86-moradores-de-rua,-diz-sas>. Acesso em: 03 mai. 2018.

SERVIÇO ESPECIALIZADO DE ATENDIMENTO A PESSOA EM SITUAÇÃO DE RUA. Dados sobre a população em situação de rua. [mensagem pessoal]. Mensagem recebida por <creaspop@presidenteprudente.sp.gov.br> em 03 mai. 2018. 